\title{
Research of Microgrid Stability with Voltage Sag Detection using Instantaneous Features Extraction
}

\author{
M.Kumudwathi, G.Sreenivasan, V.Ganesh
}

\begin{abstract}
With the inexorably serious energy shortage and environment contamination, the wide utilization of the well known sustainable power sources are considered as successful approaches to improve the energy and environment circumstance. The negative impact on the system stability couldn't be overlooked for their irregular, fluctuant and arbitrary attributes. Intending to think about the strength of microgrid with access of Instantaneous Features Extraction is one of the most productive methods for successful utilization of these grids.

In this way a proactive tracking, counteract fault ride-through the sustainable sources, bring about limiting downtime and improving the profitability. In this unique situation, this paper proposes Instantaneous Features Extraction calculation for the identification of voltage droops as they are the most frequently experienced power quality aggravations. Hence takes into consideration early discovery of power quality degeneration improves the profitability.
\end{abstract}

Keywords: Microgrid, DG, Voltage Sag, Swell, Power quality, Stability

\section{INTRODUCTION}

In the microgrid system, the distributed generation (DG) is highly attractive research feature and is much related owed to the environmental criteria and also it become an alternative of the fossile fuel generations [1-2]. These DGs are not centrally connected and controlled but these are connected at the end user location, therefore it is playing a major role in distributed electrical power system. The expansion of this DGs leads to the idea of microgrid [3]. The microgrid connected with many resources operating in parallel along with the power converters coupled will have dissimilar control objectives as explained in [4-6].The major control strategies are like master slave, multi agent, droop control and sag or swell detection control are discussed in [7-8].

The major considerations in the organization of microgrids are their ease of use, consistency, stability and profitability; in order to achieve the end user requirements according to PQ standards especially in terms of stability. In this context, one such essential requirement is automation of voltage sag or swell detection and indexing [9-10]

But monitoring of the voltage sags in the real time and at the remote location is become a key issues that necessities to amend to make the microgrid increasingly insightful, steady

\footnotetext{
Revised Version Manuscript Received on August 19, 2019.

M. Kumudwathi, PhD Scholar, JNTUA-Anantapur, A.P. India.(email: kumuda.mannala@gmail.com)

Dr. G. Sreenivasan, Professor, SRIT, A.P. India.(email: gsn.anusree@gmail.com)

Dr. V. Ganesh, HOD, Dept.of EEE, JNTUA-pulivendula, A.P. India.(email: ganivg@gmail.com)
}

and self healing. This can be done with the help of the sophisticated computer monitoring system [11]. A wide scope of advancements and computation strategies proposed from contemporary power systems for the discovery of voltage droops [12]. The inputs to the above methods are basic electrical quantities signatures and their analysis. These electrical quantities study generally includes the utilization of reference frame transformations, for example, Park's vector [13] or three-phase symmetrical segments or space vector [14], and different strategies dependent on them. These strategies are having numerous downsides [12]. As voltage droop study lead to transient occurrence [15], it appears that the emphasis ought to be on transient signal processing strategies. In this exasperating and transient situation, it is proposed to evaluate the stability of the system the signal processing with the fast recovery sags computation technique is proposed in this paper. With the fast self healing system with signal processing computation method particular features will be extricated from the instant power for voltage droops location and categorization stability of the system is improved.

\section{VOLTAGE SAGS DETECTION TECHNIQUES \&RESULTS}

A wide range of the voltage droops and their marks are depicted in Fig. 1. During a voltage droop three- system balanced conditions are never exists and prompting conceivable unfortunate outcomes on the client end-loads and on the smart grid itself.

To define the ability of the voltage sag and swell detection techniques we need to assess them with the different fault data. One such assessment is shown in figure 2. The gained voltage and currents when a fault happens on a transmission line during a fault causing voltage droop. Since voltage droops impact emerges in voltages and currents, it appears to be write the three-phase instantaneous power given by

$$
p(t)=\sum_{k=a, b, c} V_{k}(t) i_{k}(t)
$$

In Fig.3, the instantaneous voltages, currents and power are shown before, during and after the fault clearance. From the figure it is clearly shown that the detection of voltage sag duration is can be traced easily by tracking the power Instantaneous Amplitude (IA). Analysis of this IA allows the extraction of the fault characterization using statistical features. In this specific circumstance, there exist numerous 
IA estimation procedures in the literature and the most famous incorporate Hilbert Transform (HT). Later, many literatures show [11-15] different approaches of estimation of the voltage sag profiles.

Further, with the employment of the digital computation techniques a new adopted technique is discussing here for extraction of instantaneous values of the power hence the characterization of the voltage sag.

Each and every segment is used for the voltage sags characterization. As it is observed that the first segment is free from fault so the first segment IA of power waveform is then compared with the other segments IA. A total of 12 segments are considered for the calculation of the voltage sags and their characterization. Each and every segment is compared with the first non fault segment.

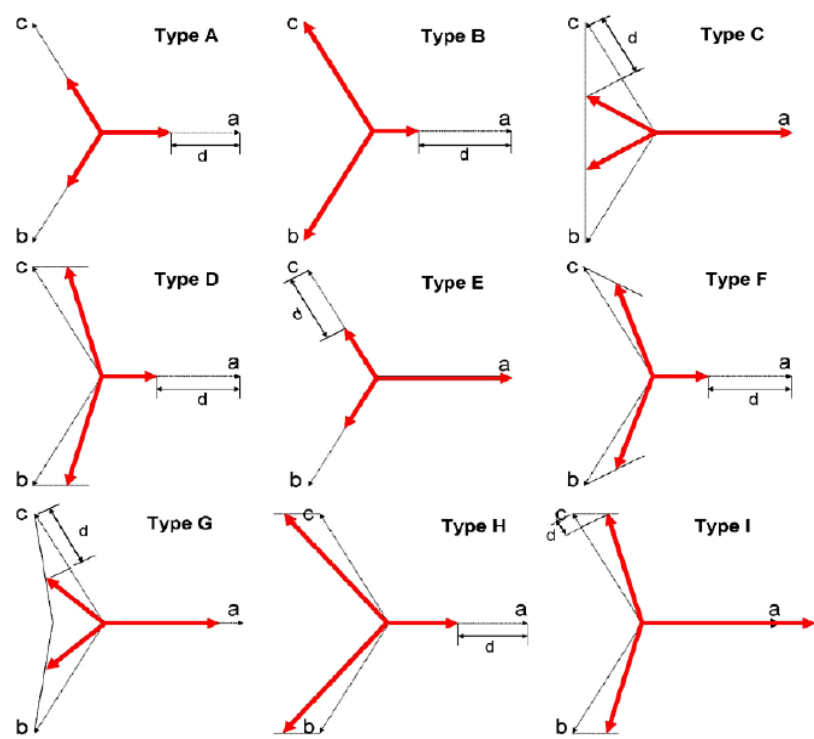

Fig.1. Different types of major voltage sag signatures
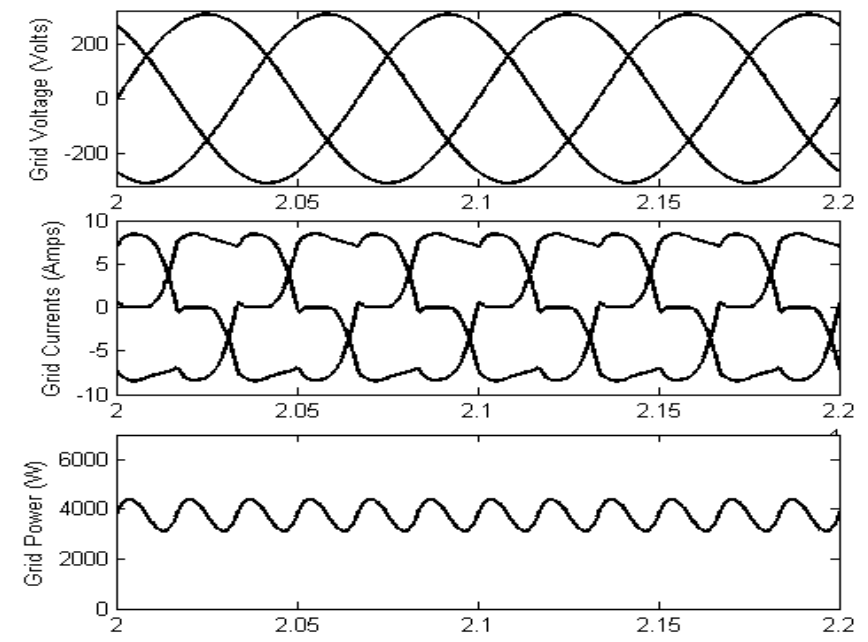

Fig2: Instantaneous values of phase voltages, currents, and the total instantaneous power before fault.
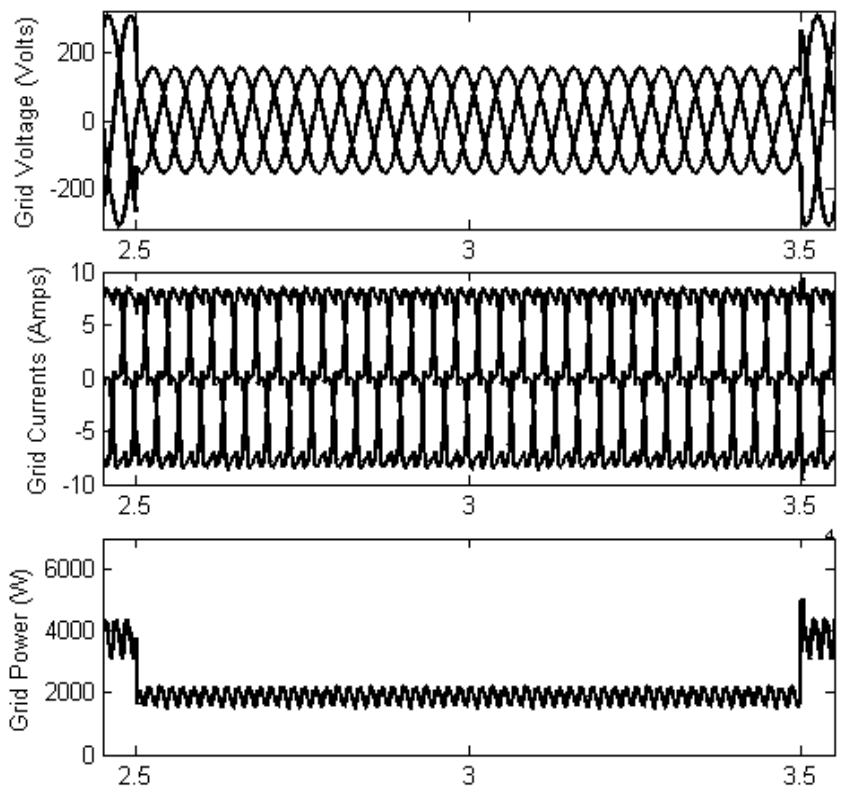

Fig. 3. Instantaneous values of phase voltages, currents, and the total instantaneous power before, during and after voltage sag.

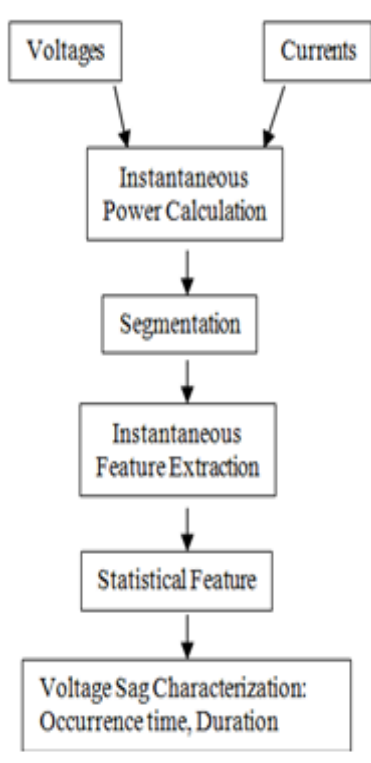

(a)

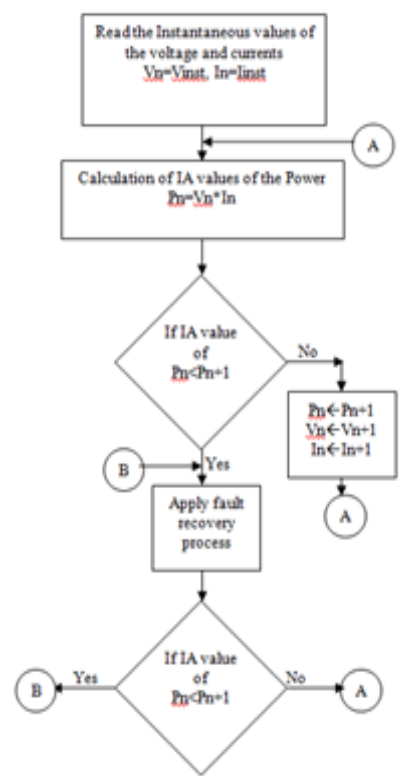

(b)
Fig. 4 (a). Adopted approach for feature extraction. (b) Process of the fault recovery with the adopted approach

Based on the variation in the comparison then fault recovery is done with the conventional or other improvised techniques. In fig.5 (a) it is shown only with fault and without fault conditions. But in the fig.5 (b) it is shown the fault recovery also. The process of the fault recovery with the adopted approach is shown in the flowchart in fig.4 (b).

\subsection{Adopted approach for feature extraction}

This adopted approach is of a conventional signal processing approach and is executed the help of the MATLAB code, which is explained in Fig.4. It is used to estimate the instantaneous amplitude of the power signal. The discrete wave form of the power signal is traced and then the

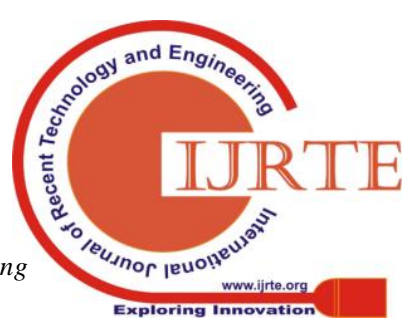


waveform is split in to definite number of segments.

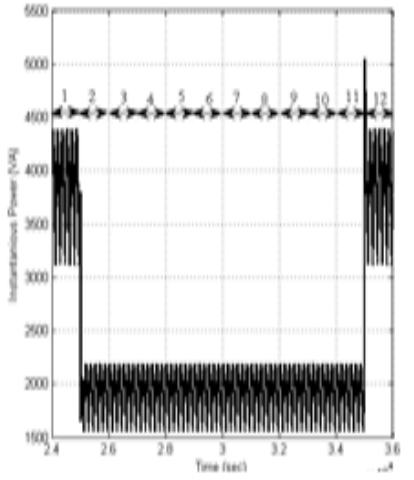

(a)

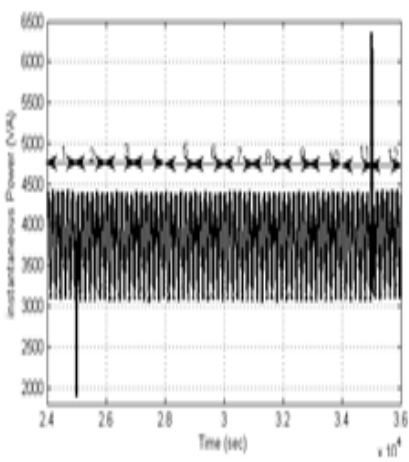

(b)
Fig.5(a). The discrete wave form of the power signal with segmentation, Fig.5(b). the discrete waveforms of the power signal during the fault recovery with segmentation.

From the results it seems that the adopted approach using the IA can be considered a reliable approach for the detection of the sag. The FFT analysis shows the characterizes the harmonics that are presented in the waveform before, after and during the fault. The $\%$ of THD of the voltage waveform is shown in Fig.7, it can be seen that the magnitudes of the harmonics at lower order are very high during fault and there is no fault recovery is takes place or any other voltage calculation method is introduced. In Fig.6 (a). It is observed that the THD value is 29.66 and it is considerably very high. Later after employing the voltage sag method along with the fault recovery the THD is reduced to 7.42 as shown in fig.6 (b).

\section{CONCLUSION}

In this paper, A new adopted approach for the measurement of the voltage sag is simple and easy approach in the microgrid concept. Adding to the other fault recovery schemes is this adopted approach enhances the fast healing and provides a better stability in order of the harmonics is also reduced in the microgrid system.
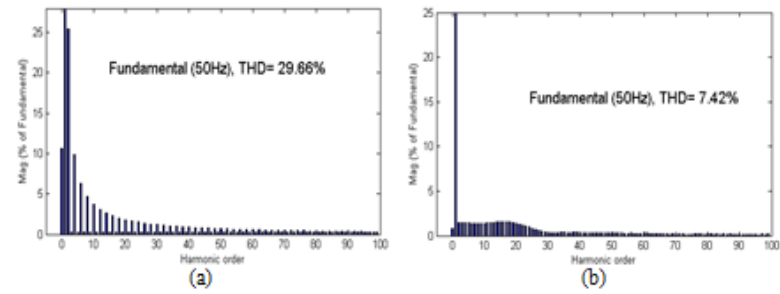

Fig.6 (a) FFT analysis of the voltage waveform under fault condition, Fig. 7(b) FFT analysis of the voltage waveform after recovery from fault

\section{REFERENCES}

1. R. H. Lasseter and P. Piagi, "Providing premium power through distributed resources," in Proc. IEEE 33rd Hawail Int. Conf. System Sciences (HICSS'00), , pp. 1-9. (2000)

2. S. R. Wall, "Performance of inverter interfaced distributed generation," in Proc. IEEE/PES-Transmission and Distribution Conf. Expo. pp. 945-950. (2001)

3. R. Lasseter, "Microgrids", Power Engineering Society Winter Meeting 2002. IEEE, vol. 1, pp. 305-308, (2002).

4. P. Piagi and R. H. Lasseter, "Autonomous Control of
Microgrids", IEEE Power Engineering Society General Meeting, pp. 8, (2006).

5. J. A. P. Lopes, C. L. Moreira, and A. G. Madureira, "Defining Control Strategies for MicroGrids Islanded Operation", IEEE Transactions on Power Systems, vol. 21, pp. 916-924,(2006).

6. K. De Brabandere, K. Vanthournout, J. Driesen, G Deconinck, and R.Belmans, "Control of Microgrids", IEEE Power Engineering Society General Meeting, pp. 1-7, (2007).

7. Daniel E. Olivares, A. Mehrizi-Sani, Amir H. Etemadi, "Trends in microgrid control", IEEE Transactions on Smart Grid, vol. 5, no. 4, pp. 1905-1919, (2014).

8. P. Borazjani, N. I. A. Wahab, H. B. Hizam, A. Bt Che Soh, "A review on microgrid control techniques", Proc. IEEE Innov. Smart Grid Technol. Asia (ISGT Asia), pp. 749-753, (2014).

9. E. Gómez-Lázaro, J.A. Fuentes, A. Molina-García, M. Cañas-Carretón, "Characterization and visualization of voltage dips in wind power installations," IEEE Trans. Power Delivery, vol. 24, n4, pp. 2071-2078, October 2009.

10. V. Ignatova, P. Grangon and S. Bacha, "Space vector method for voltage dips and swells analysis," IEEE Trans. Power Delivery, vol. 24, n4, pp. 2054-2061, October (2009).

11. M.G. Simões and al., "A comparison of smart grid technologies and progresses in Europe and the US," IEEE Trans. Industry Applications, vol. 48, n 4, pp. 1154-1162, July/August (2012).

12. C. Fitzer, M. Barns and P. Green, "Voltage sag detection technique for a dynamic voltage restorer," IEEE Trans. Industry Applications, vol. 40, $\mathrm{n}^{\circ} 1$, pp. 203-212, January/February (2004).

13. G.A. Orcajo, J.M. Cano, M.G. Melero, M.F. Cabanas, C.H. Rojas, J.F. Pedrayes and J.G. Noriella, "Diagnosis of electrical distribution network short circuits based on voltage Park's vector," IEEE Trans. Power Delivery, vol. 27, n² 4, pp. 1964-1972, October (2012).

14. V. Ignatova, P. Grangon and S. Bacha, "Space vector method for voltage dips and swells analysis," IEEE Trans. Power Delivery, vol. 24, n4, pp.2054-2061, October (2009).

15. C. Muscas, "Power quality monitoring in modern electric distribution systems," IEEE Instrumentation and Measurement Magazine, vol. 13, n5, pp. 19-27, October (2010). 